\title{
Fish Oil Prophylaxis Protects against 3-Nitropropinic Acid-Induced Oxidative Impairments in Striatum and Cerebellum in Male Rat Brain \\ Denny Joseph Manual Kollareth ${ }^{1 *}$, Mythri Rajeswara Babu' ${ }^{2}$, MM Srinivas Bharath ${ }^{2}$ and Muralidhara ${ }^{1}$ \\ ${ }^{1}$ Department of Biochemistry, CSIR - Central Food Technological Research Institute (CFTRI), Mysuru, Karnataka, India \\ ${ }^{2}$ Department of Neurochemistry, National Institute of Mental Health and Neurosciences (NIMHANS), Bengaluru, Karnataka, India
}

\begin{abstract}
Increasing evidence supports a role for fish oil (FO) and the $n-3$ polyunsaturated fatty acids ( $\mathrm{n}-3$ PUFA) -docosahexaenoic acid (DHA) and eicosapentaenoic acid (EPA), in protecting against neurodegeneration. However, experimental evidence on their neuroprotective efficacy in neurotoxin models is rather limited. In the present study, we examined whether pretreatment with n-3 PUFA in SH-SY5Y cells and FO prophylaxis in rats would render them less susceptible to 3-nitropropionic acid (a mitochondrial toxin, NPA) exposure. Cells pretreated with DHA/EPA were more resistant to NPA-induced perturbations in antioxidant defenses and exhibited higher survival rate. Further, we validated these findings among growing rats provided with $\mathrm{FO}(4 \mathrm{~mL} / \mathrm{kg} \mathrm{bw})$ prophylaxis for 4 weeks and subjected to NPA challenge $(25 \mathrm{mg} / \mathrm{kg}$ bw/d during last $4 \mathrm{~d})$. Interestingly, FO prophylaxis offered significant protection against NPA -induced oxidative dysfunctions and depleted dopamine levels in striatum. Based on our in vitro and in vivo findings, we hypothesize that the protective effect of FO may be wholly or in part related to its potential to enhance GSH, thiols and antioxidant defenses in specific regions of brain of rats. Thus FO prophylaxis is likely to offer a therapeutic advantage as a neuroprotective strategy under oxidative stress-mediated neurodegenerative conditions.
\end{abstract}

Keywords: SH-SY5Y cells; Fish oil; Brain; 3-Nitropropionic acid; Oxidative stress

Abbreviations: DHA: Docosahexaenoic acid; EPA: Eicosapentaenoic acid; NPA: 3- Nitropropionic acid; MDA: Malondialdehyde; ROS: Reactive oxygen species; CTR: Control; n-3 PUFA: n-3 Polyunsaturated fatty acids; FO: Fish oil; Conc.: Concentration; NO: Nitric oxide; PC: Protein carbonyls.

\section{Introduction}

Fish oil (FO) provides a rich source of $n-3$ polyunsaturated fatty acids (n-3 PUFA), docosahexaenoic acid (DHA) and eicosapentaenoic acid (EPA) which are vital for normal brain development/function and generally associated with reduced risk of the development of various neurological disorders [1]. DHA accumulates in high concentration in brain and retina and alterations in brain DHA levels are positively associated with changes in cognitive and behavioral performance [2]. DHA, EPA and their metabolites are demonstrated to possess anti-excitotoxic, antioxidant, anti-apoptotic, and anti-inflammatory properties [3]. Further, DHA is shown to reduce oxidative stress in the brain [4], and recent experimental evidence ascribes a neurotrophic action of EPA [5].

3-nitropropionic acid (NPA) is an irreversible inhibitor of succinate dehydrogenase (SDH), a mitochondrial Complex II enzyme which blocks the transport of electrons in oxidative phosphorylation. Prolonged energy impairment induced by NPA is sufficient to produce most of the clinical and pathophysiological hallmarks of Huntington's Disease (HD) $[6,7]$. The mechanisms of neurotoxicity induced by NPA have been shown to include the exhaustion of adenosine triphosphate, mitochondrial membrane depolarization, dysregulation of intracellular calcium homeostasis, calpain activation and the release of pro-apoptotic proteins from mitochondria [8]. A body of experimental evidence suggests that oxidative stress plays a vital role in the manifestation of NPA induced neurotoxicity [9]. Accordingly, attempts have been made to ameliorate the NPA- induced oxidative stress and neurotoxicity using various phytochemicals and antioxidants $[10,11]$.
Human neuroblastoma SH-SY5Y is a dopaminergic cell line extensively used as an in vitro model for neurotoxicity studies. Recently, SH-SY5Y cells were used to investigate the protective mechanisms of succinobucol, a lipid lowering drug, against NPA induced oxidative stress and mitochondrial dysfunction [12]. Experimental evidence has shown that both DHA/ EPA offered significant protection against induced toxicity in SH-SY5Y cells $[13,14]$. Cells exposed to DHA showed significant concentration-dependent increase in the percentage of cells with longer neurites [15]. However, studies describing the efficacy of DHA and EPA to modulate endogenous oxidative markers in cell models are limited.

In view of the above, we first examined whether pretreatment with low concentrations of DHA and EPA has the potential to protect SH-SY5Y cells against 3-NPA induced cell death and oxidative stress. Subsequently, we validated our premise whether short-term prophylaxis of growing male rats with oral supplements of FO renders the brain less vulnerable to NPA-induced oxidative dysfunctions and neurotoxicity. The neuroprotective propensity of FO was assessed biochemically in terms of oxidative stress, mitochondrial dysfunctions and neurotoxicity in selected brain regions viz., cerebellum and striatum since we have previously evidenced relatively higher impact of NPA in these regions employing this dosing regimen [9].

*Corresponding author: Denny Joseph Manual Kollareth, Institute of Human Nutrition, Columbia University Medical Center, NY, New York, USA, Tel: +12123053961; Fax: +12123056772; E-mail: dennykm83@gmail.com

Received April 24, 2017; Accepted May 03, 2017; Published May 08, 2017

Citation: Kollareth DJM, Babu MR, Bharath MMS, Muralidhara M (2017) Fish Oil Prophylaxis Protects against 3-Nitropropinic Acid-Induced Oxidative Impairments in Striatum and Cerebellum in Male Rat Brain. Neurochem Neuropharm 3: 116.

Copyright: (c) 2017 Kollareth DJM, et al. This is an open-access article distributed under the terms of the Creative Commons Attribution License, which permits unrestricted use, distribution, and reproduction in any medium, provided the original author and source are credited. 


\section{Materials and Methods}

\section{Chemicals}

Thiobarbituric acid (TBA), 1,1,3,3-tetramethoxy propane (TMP), 2',7'-dichlorofluorescein (DCF), 2',7'-dichlorofluorescein diacetate (DCFH-DA), docosahexaenoic acid (DHA), eicosapentaenoic acid (EPA), 3-nitropropionic acid (NPA), 3-(4,5-dimethylthiazol-2-yl)2,5-diphenyltetrazolium bromide (MTT) were purchased from $\mathrm{M} / \mathrm{s}$ Sigma Chemical Co. St. Louis, USA. All other chemicals used were of analytical grade.

\section{Experiments in SH-SY5Y cells}

SH-SY5Y cells were grown in our laboratory and maintained as described earlier [16]. Briefly, cells were grown in Dulbecco's Modified Eagle's medium (DMEM) supplemented with $2 \mathrm{mM}$ L-glutamine, penicillin (20 units $/ \mathrm{ml})$, streptomycin $(20 \mathrm{mg} / \mathrm{ml})$, and $15 \%$ ( $\mathrm{vol} / \mathrm{vol})$ heat-inactivated fetal calf serum. Cells were maintained at $37^{\circ} \mathrm{C}$ in a saturated humidity atmosphere containing $5 \% \mathrm{CO}_{2} / 95 \%$ air. For the determinative studies, cells were collected by trypsinization and defined number of cells was grown in media containing the test compound.

Cell viability was measured employing MTT reduction assay (in 96 well plates) as described previously [17]. In a preliminary study, the effect of DHA and EPA on viability of cells was determined employing concentrations ranging from 5- $50 \mu \mathrm{M}(24 \mathrm{~h})$. Further, cells were exposed to NPA at various concentrations for $24 \mathrm{~h}$ to determine the LC50 value. To study the modulatory effect of DHA and EPA against NPA toxicity, cells were pre-exposed $(2 \mathrm{~h})$ with DHA and EPA at various concentrations followed by co-exposure with NPA (4 mM) for $24 \mathrm{~h}$. Both EPA and DHA did not offer protection against NPA induced cell death at lower concentrations $(5,10 \mu \mathrm{M})$. Hence, higher concentrations $(25$ and $50 \mu \mathrm{M})$ of these fatty acids were selected for further determinative studies.

\section{Efficacy of FO prophylaxis against NPA model of neurotoxicity in rats}

Animals and care: Growing male Wistar rats (4 wks-old) drawn from the stock colony of our animal facility were housed in rectangular polypropylene cages kept on racks built of slotted angles, in a controlled atmosphere with a $12 \mathrm{~h}$ light / dark cycle. They were acclimatized for 3 days prior to the start of the experiment. The animals were maintained on a commercial powdered diet and tap water ad libtum. The experiments were conducted strictly in accordance with approved guidelines by the "Institute Animal Ethical Committee" regulated by the Committee for the Purpose of Control and Supervision of Experiments on Animals (CPCSEA), Ministry of Social justice and Empowerment, Government of India, India.

Fish oil (FO) composition and dosages: Cod liver oil purchased from Seven Seas (Seacod) was used throughout the study and gas chromatography analysis showed the composition as 7.5\% EPA and 6.5\% DHA. We used FO at a dosage of $4 \mathrm{~mL} / \mathrm{kg}$ bw/d for 4 wks and the dosage selection was based on our previous study [18].

Experimental design: Growing rats (4 weeks-old) were assigned to control and FO prophylaxis groups and provided with oral supplements of FO at a dosage of $4 \mathrm{~mL} / \mathrm{kg}$ bw/d for 4 wks. After 28 days, rats of both control and FO prophylaxis groups were administered (i.p.) with NPA at a dosage of $25 \mathrm{mg} / \mathrm{kg}$ bw (i.p.) for 4 days. The selection of this dosage was based on our preliminary standardizations and literature [19]. Physiological saline was administered to control rats (i.p). FO supplements were continued during NPA administration. On day 33 , the animals were sacrificed, brain excised and brain regions viz., cerebellum $(\mathrm{Cb})$ and striatum $(\mathrm{St})$ were dissected over ice. From each brain region, cytosol and mitochondrial fractions were prepared and subjected to quantification of various biochemical parameters.

\section{Biochemical measurements}

Cytosolic fractionation of SH-SY5Y cells: Cells were harvested by trypsin treatment; cell pellet was re-suspended in phosphate buffered saline ( $\mathrm{pH} 7.4)$ and sonicated for two cycles of $5 \mathrm{~s}$ each. The samples were centrifuged $\left(10000 \mathrm{Xg}, 10 \mathrm{~min}, 4^{\circ} \mathrm{C}\right)$ and the supernatant was used for biochemical estimations.

Cytosolic/mitochondrial fractionation of brain regions: Mitochondria were prepared by differential centrifugation as previously described with minor modifications [20]. Briefly a $10 \%$ homogenate of the brain regions were prepared in ice-cold Tris-Sucrose buffer $(0.25$ $\mathrm{M}, \mathrm{pH}$ 7.4) using a glass-teflon grinder at $4^{\circ} \mathrm{C}$. The homogenate was centrifuged at $1000 \mathrm{Xg}$ for $10 \mathrm{~min}$ at $4^{\circ} \mathrm{C}$ to obtain the nuclear pellet. The supernatant was further subjected to centrifugation at $10,000 \mathrm{X} \mathrm{g}$ for 20 min at $4^{\circ} \mathrm{C}$ to obtain the mitochondrial pellet and cytosol. The pellet was washed three times in Mannitol-Sucrose-HEPES buffer ( $\mathrm{pH} 7.4$ ), resuspended in the same buffer and stored.

\section{Markers of oxidative stress}

The extent of lipid peroxidation was measured using thiobarbituric acid $(0.8 \% \mathrm{w} / \mathrm{v})$ and quantified as malondialdehyde equivalents using 1,1,3,3-tetramethoxy propane as the standard [21]. For determination of reactive oxygen species, cytosol/mitochondrial protein $(0.2 \mathrm{mg})$ suspended in Locke's solution was incubated with dihydrodichlorofluorescein diacetate $(5 \mathrm{mM})$ for $30 \mathrm{~min}$ at room temperature. The fluorescence intensity measured at excitation (480 $\mathrm{nm})$ and emission wavelengths $(530 \mathrm{~nm})$ were quantified from a dichlorofluorescein standard curve [9]. The hydroperoxide levels in cytosol/mitochondrial fractions were determined as described previously [22]. Nitric oxide levels were measured in brain cytosol and mitochondria as per the specifications employing commercially available Griess reagent (M/s Sigma Chemicals, St. Louis, USA) and quantified from a sodium nitrite standard curve.

Protein oxidative damage: protein carbonyls content: Protein carbonyl (PC) content in the brain regions were determined as described earlier [23]. Cytosol sample (equivalent to $0.5 \mathrm{mg}$ protein) was incubated with 2,4-dinitrophenyl hydrazine (DNPH) for $60 \mathrm{~min}$ at room temperature. Following precipitation by adding $20 \%$ trichloroacetic acid, the pellet was washed with acetone and dissolved in $1 \mathrm{~mL}$ of tris buffer containing sodium dodecyl sulphate $(8 \% \mathrm{w} / \mathrm{v}, \mathrm{pH} 7.4)$. The absorbance was measured at $360 \mathrm{~nm}$ and expressed as nmol carbonyls/mg protein $(\varepsilon-22000 \mathrm{nmol} / \mathrm{cm})$.

Determination of reduced glutathione (GSH): GSH levels were quantified by a fluorimetric method [24]. Cytosol (equivalent to 0.1 mg protein) was added to $1 \mathrm{~mL}$ formic acid $(0.1 \mathrm{M})$ and centrifuged at $10,000 \mathrm{Xg}$ for $10 \mathrm{~min}$. An aliquot of the supernatant was used for the assay. Concentration of GSH was calculated from the standard curve and the expressed as $\mu \mathrm{g} \mathrm{GSH} / \mathrm{mg}$ protein.

\section{Activities of antioxidant enzymes}

Superoxide dismutase (SOD) activity was measured by monitoring the inhibition of quercetin autoxidation [25]. Catalase (CAT) activity 
was assayed by the method of Aebi [26] and expressed as nmol of hydrogen peroxide decomposed per min per mg protein $(\varepsilon-43.6 / \mathrm{mM} /$ $\mathrm{cm}$ ). Thioredoxin reductase (TRR) activity was measured as described previously [27]. Glutathione-S-transferase (GST) activity was measured by monitoring the rate of enzyme-catalyzed conjugation of reduced glutathione with 1-chloro-2, 4-dinitrobenzene, and expressed as $\mu \mathrm{mol}$ of conjugate formed per min per mg protein $(\varepsilon-9.6 / \mathrm{mM} / \mathrm{cm})[28]$. Glutathione peroxidase (GPx) activity was measured as described previously [29].

Acetylcholinesterase (AChE) activity: The activity of AChE was determined according to the method of Ellman et al. [30] by taking $1 \mathrm{~mL}$ reaction mixture containing phosphate buffer $(0.1 \mathrm{M}, \mathrm{pH} 8.0)$, DTNB $(10 \mathrm{mM})$, cytosol $(0.1 \mathrm{mg})$ and acetylthiocholine iodide $(150 \mathrm{mM})$. Change in absorbance was monitored for $3 \mathrm{~min}$ at $412 \mathrm{~nm}$.

Dopamine (DA) estimation by HPLC: Dopamine (DA) levels in the cytosol of striatum were analyzed [31] using HPLC system (Model Shimadzu LC-10 Avp, UV visible detector (SPD-10 Avp), Pump (LC10 ATvp), Shimadzu, Japan) linked to an injection valve with $20 \mu \mathrm{l}$ sample loop (Model 7125, Rheodyne, CA, USA). Sample was injected to a reversed-phase column (Make: 'Discovery' Supelco Sigma-Aldrich; C-18, $25 \mathrm{~cm}-4.6 \mathrm{~mm}, 5 \mathrm{~mm}$ ) accessorized with an ultraviolet detector $(280 \mathrm{~nm})$. Analyses were all performed at room temperature. The sample was eluted using the mobile phase $0.2 \%$ aqueous trifluoroacetic acid and methanol $(70: 30, \mathrm{v} / \mathrm{v})$ at the flow rate of $1 \mathrm{~mL} / \mathrm{min}$. The peak corresponding to DA would appear between 2.6 and $2.9 \mathrm{~min}$. DA levels were calculated from an external standard curve.

Effect on succinate dehydrogenase activity: The activity of Succinate dehydrogenase (SDH) was determined as described earlier [32] with minor modifications. Briefly, mitochondrial protein $(0.05 \mathrm{mg})$ was incubated with $50 \mathrm{mM}$ potassium phosphate $(\mathrm{pH}$ 7.4) containing sodium succinate $(0.01 \mathrm{~mol} / \mathrm{L})$ and p-iodonitrotetrazolium violet $(2.5 \mu \mathrm{g} /$ $\mathrm{mL}$ ) for $10 \mathrm{~min}$. The reaction was stopped by addition of $10 \%$ TCA. The color obtained was extracted with ethyl acetate:ethanol:trichloroacetic acid (5:5:1, v:v:w) and measured at $490 \mathrm{~nm}$. The activity was expressed as $\mathrm{OD} / \mathrm{mg}$ protein.

Effect on activity of ETC enzymes: The activities of NADHcytochrome $\mathrm{C}$ reductase and succinate-cytochrome $\mathrm{C}$ reductase were measured in brain mitochondria as described previously [33]. Briefly mitochondrial protein $(0.1 \mathrm{mg})$ was added to phosphate buffer $(0.1 \mathrm{M}$, $\mathrm{pH} 7.4)$ containing NADH $(0.2 \mathrm{mM})$ and $\mathrm{KCN}(1 \mathrm{mM})$. The reaction was initiated by the addition of $0.1 \mathrm{mM}$ cytochrome $\mathrm{C}$ giving a final volume of $1 \mathrm{~mL}$ reaction mixture and decrease in absorbance was monitored for $3 \mathrm{~min}$ at $550 \mathrm{~nm}$. The activity was expressed as $\mathrm{n}$ mol cytochrome $\mathrm{C}$ reduced $/ \mathrm{min} / \mathrm{mg}$ protein $(\varepsilon-19.6 / \mathrm{mM} / \mathrm{cm})$. To determine the activity of succinate- cytochrome $\mathrm{C}$ reductase, the substrate succinate $(20 \mathrm{mM})$ was used.

\section{Determination of protein}

Protein concentration of cytosol and mitochondria were determined by the method of Lowry et al. [34] using bovine serum albumin as standard.

\section{Statistical analysis}

Results are represented as means \pm standard error (SE) for each experimental group. The data was analyzed by one-way ANOVA followed by a post hoc Dunnet and Tukey tests to compare the control and treatment groups; p-values less than 0.05 were considered as statistically significant. All statistical analysis was performed using SPSS statistical software package version 17.0.

\section{Results}

\section{Pretreatment of SH-SY5Y cells modulates endogenous levels} of oxidative markers and NPA induced oxidative stress

Fatty acids enhance cell viability: Exposure of cells to varying concentrations $(5-50 \mu \mathrm{M})$ of DHA or EPA did not have any significant effect on cell viability (Figure 1A and 1B). The LC50 for NPA was determined as $4 \mathrm{mM}$ in this cell model (Figure 2A). At lower concentrations $(5,10 \mu \mathrm{M})$, both EPA and DHA did not offer any protection against NPA exposure (Hence data not shown). However, at higher concentrations (25 and $50 \mu \mathrm{M})$, the fatty acids offered significant protection against NPA toxicity (Figure 2B).

DHA and EPA modulate endogenous levels of oxidative markers: We found significantly elevated GSH levels at low concentration (25 $\mu \mathrm{M})$ of DHA, while the levels were diminished with high $(50 \mu \mathrm{M})$ concentration. Although EPA diminished the levels at low $(25 \mu \mathrm{M})$ conc., the levels were unaffected at high conc (Table 1). Diminished ROS levels were evident with DHA at low conc. while the levels were significantly elevated at high conc. However, EPA treatment lowered the ROS levels at both concentrations (Table 1).

With DHA, SOD activity was found to be decreased at low conc. while the activity was elevated at high conc. In contrast, the activity was significantly reduced with EPA at both concentrations (Table 1). Further, CAT activity was enhanced with DHA at both concentrations, whereas no changes were evident with EPA. On the other hand, TRR activity was significantly elevated with both EPA and DHA at low conc., while the activity was decreased with higher conc. AChE activity was found to be significantly enhanced with both EPA and DHA at $50 \mu \mathrm{M}$ concentrations (Table 1).

Pretreatment with DHA and EPA offsets NPA -induced toxicity: NPA induced ROS levels were significantly reduced among cells exposed to DHA $(25 \mathrm{M})$ and EPA $(50 \mu \mathrm{M})$ (Table 2). Further, NPA exposure caused significant depletion of GSH levels in SH-SY5Y cells. Interestingly, DHA pretreatment significantly restored the levels at both concentrations, while EPA was effective only at high conc. Further, diminished SOD activity among NPA exposed cells were markedly improved with DHA as well as EPA at both the concentrations (Table 2). Similarly, NPA induced reduction in the CAT activity was also consistently restored with DHA and EPA at both the concentrations. Furthermore, NPA induced reduction in TRR activity was improved with DHA $(25 \mu \mathrm{M})$ while the activity levels remained further enhanced with EPA $(50 \mu \mathrm{M})$. Interestingly, NPA exposure caused marginal enhancement in the AChE activity, which was further enhanced with DHA, while the activity was completely restored with EPA (Table 2).

\section{FO prophylaxis offsets NPA-induced oxidative stress and neurotoxicity in vivo}

Attenuation of oxidative stress in striatum (St) and cerebellum (Cb): NPA administration caused significant lipid peroxidation as evident by the elevated MDA levels in both cytosol and mitochondria in striatum. Among rats given FO prophylaxis, MDA levels in cytosol were comparable to control, while it marginally diminished in mitochondria. Further, the ROS levels among NPA administered rats were markedly 

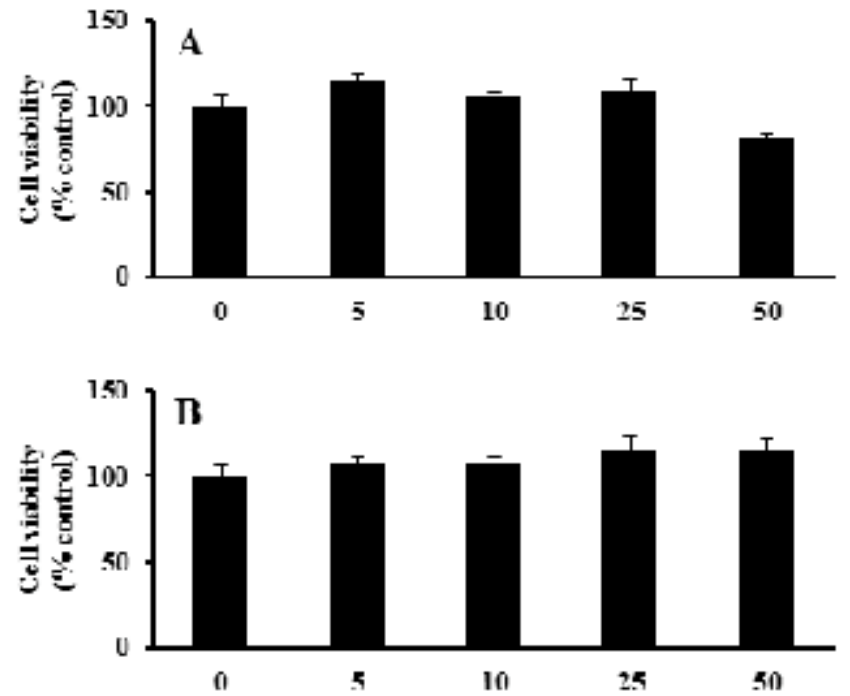

Values are mean \pm SE (6 replicates); Data analyzed by one-way ANOVA followed by post hoc Dunnet test;

${ }^{*} p<0.05$, Compared to Control group

Figure 1: Effect of DHA (A) and EPA (B) exposure (DHA/EPA, 5-50 $\mu \mathrm{M})$ on viability of $\mathrm{SH}-\mathrm{SY} 5 \mathrm{Y}$ cells.
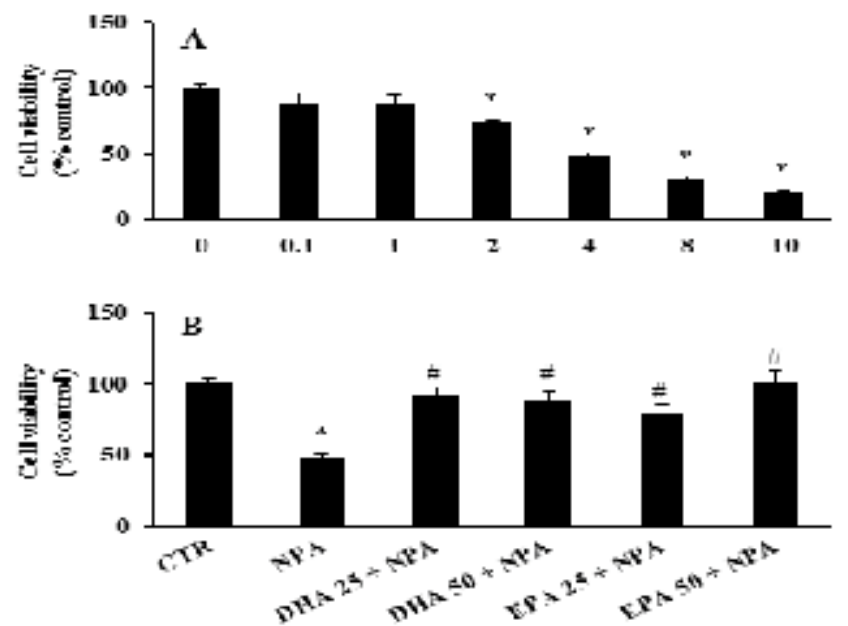

Values are mean $\pm S E$ (6 replicates); Data analyzed by one-way ANOVA followed by post hoc Dunnet (A) and Tukey (B) test; " $p<0.05$, Compared to Control group; ${ }^{*} \mathrm{p}<0.05$, Compared to NPA alone group

Figure 2: 3-nitropropionic acid (NPA, 0.1-10 mM) induced cytotoxicity (A) and modulatory effect of DHA/ EPA pretreatment on cell viability in SH-SY5Y cells (B) against NPA (DHA/ EPA, 25 \& $50 \mu \mathrm{M}$; NPA, $4 \mathrm{mM}$ ).

(71\%) elevated in St, while no such increase was evident among FO prophylaxis rats. However, no significant changes in ROS levels were noticeable in the mitochondria. Likewise, hydroperoxide levels were elevated in both cytosolic and mitochondrial fractions with NPA and FO prophylaxis offered complete protection (Table 3).

In contrast, MDA levels in $\mathrm{Cb}$ were elevated only in the cytosol among NPA administered rats and FO prophylaxis did not offer any protection. Further, no change in ROS levels was evident in both the fractions among NPA administered rats. However, the levels in the cytosol were diminished below the basal levels with FO prophylaxis. NPA administration did not have any effect on HP levels in both cytosol and mitochondria (Table 3).

Modulatory effect on protein carbonyls and nitric oxide levels: Protein carbonyl levels were elevated only in St among NPA administered rats, and the levels were significantly diminished below the basal levels with FO prophylaxis (Figure 3A). Further, NPA administration resulted in elevated NO levels in both brain regions, while the levels with FO prophylaxis were completely normal only in St (Figure 3B).

Effect on GSH and total thiol levels: NPA caused marginal elevation in GSH and total thiol levels in St and FO prophylaxis did not have any effect. However, in Cb, both GSH and total thiol levels were significantly depleted among NPA administered rats. Interestingly the levels were completely restored to normalcy among rats given FO prophylaxis (Figure 3C and 3D).

Effect on activities of antioxidant enzymes: Data on the activity levels of antioxidant enzymes and AChE enzyme are presented in Table 4. Among NPA administered rats, GPx activity was reduced in St, while no change ensued in $\mathrm{Cb}$. However, the activity was significantly enhanced in both the regions with FO prophylaxis (Table 4). Interestingly, in St, GR activity was significantly enhanced with FO prophylaxis under NPA exposure. Further, reduced GST activity in $\mathrm{Cb}$ was completely normalized among FO rats. NPA significantly enhanced SOD activity in $\mathrm{St}$, while it was reduced in $\mathrm{Cb}$ and $\mathrm{FO}$ prophylaxis completely normalized the activity only in St (Table 4). Further, reduced CAT activity in both regions was partially restored with FO prophylaxis. However, reduced TRR activity in St and Cb were significantly restored with FO.

Modulatory effect on AChE activity and dopamine (DA) levels: AChE activity in St was significantly enhanced among NPA administered rats, while no effect was evident in $\mathrm{Cb}$. However, the activity was completely normalized with FO prophylaxis in St (Table 4). DA levels were significantly depleted (32\%) among NPA administered rats in St. Interestingly, FO prophylaxis offered significant protection against NPA induced DA depletion (Figure 4).

Effect on SDH activity and ETC enzymes: SDH activity was significantly reduced in St and $\mathrm{Cb}$ among NPA administered rats. However, FO prophylaxis failed to offer protection against NPA induced reduction in activity (Table 5). Activity of NADH- cyt $\mathrm{C}$ reductase was significantly reduced only in $\mathrm{Cb}$ among NPA administered rats and FO prophylaxis did not have any effect (Table 5). Further, succinate- cyt $\mathrm{C}$ reductase activity was significantly reduced in both $\mathrm{St}$ and $\mathrm{Cb}$ among NPA administered rats and no significant protection was observed with FO prophylaxis in both the regions (Table 5).

\section{Discussion}

DHA and EPA are conditionally essential nutrients which are found to have beneficial effects on life quality and lower the risk of cardiovascular and neurological diseases [35]. The effects of these fatty acids have been studied using various cell models. DHA/ EPA supplements are known to increase cell viability and protected against A induced toxicity in SH-SY5Y cells $[13,36]$. However, studies describing the efficacy of DHA and EPA to modulate endogenous oxidative markers in cell models are limited. Therefore, initially the potential of DHA and EPA to modulate endogenous oxidative markers in SH-SY5Y cells were determined and subsequently, their efficacy to offset NPA- induced cytotoxicity was studied.

At the tested concentrations, EPA and DHA did not affect the 

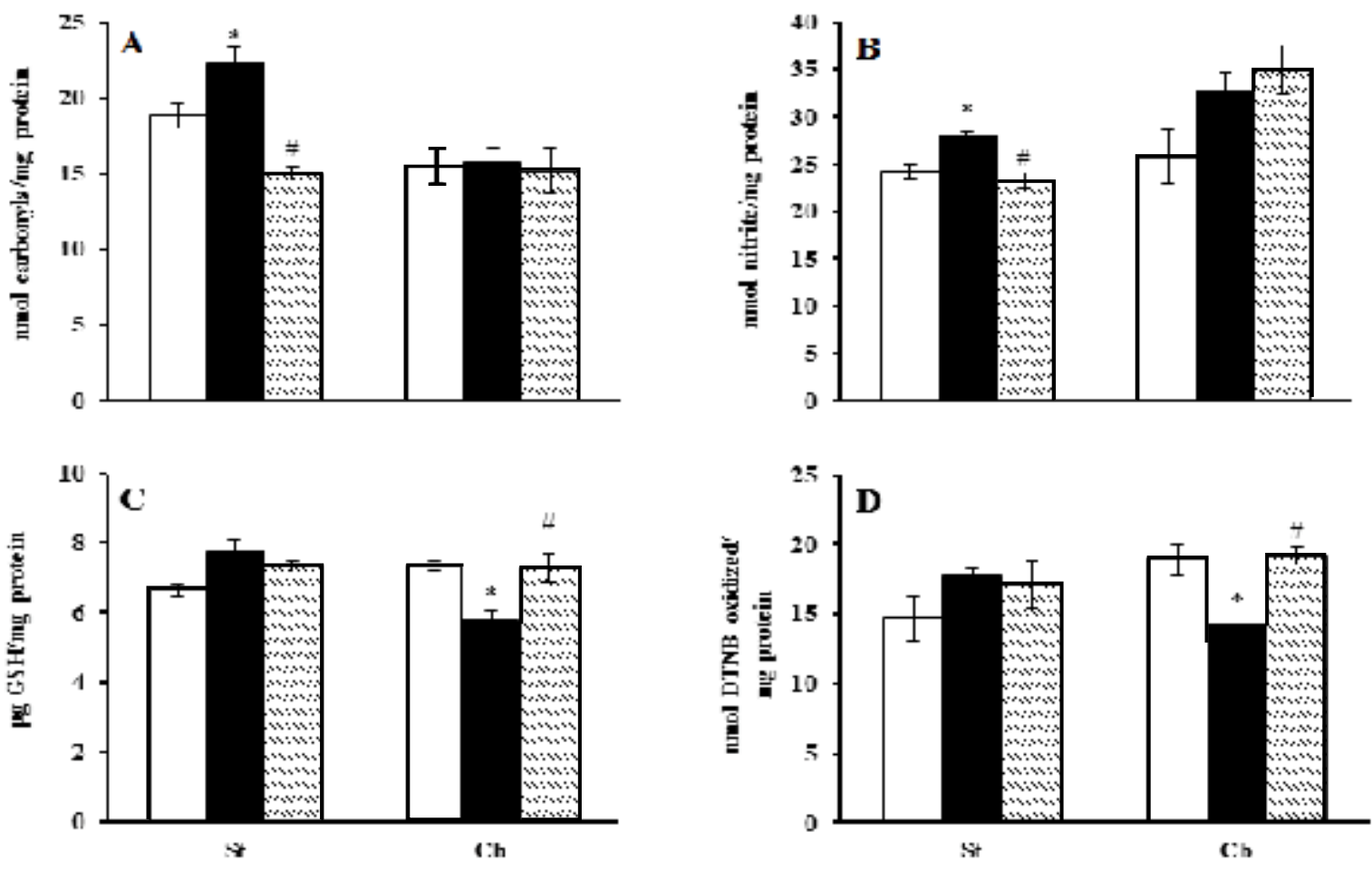

\section{ᄃ CTR $\quad$ NPA $\mathrm{NFO}+\mathrm{NP} \Lambda$}

Values are mean \pm SE $(n=6)$; Data analyzed by one-way ANOVA followed by post hoc Tukey test; * $p<0.05$ Compared to Control group; $\#<0.05$, Compared to NPA alone group

Figure 3: Effect of FO prophylaxis (4 mL/kg bw/d) on protein carbonyl (A), nitric oxide (B), GSH (C) and total thiol (D) levels in cytosol of striatum (St) and cerebellum (Cb) among NPA administered rats.

\begin{tabular}{|c|c|c|c|c|}
\hline Group & CTR & DHA 25 & DHA 50 & EPA 25 \\
\hline ROS $^{1}$ & $100.0 \pm 2.7$ & $83.5 \pm 1.9^{*}$ & $137.7 \pm 3.9^{*}$ & $75.6 \pm 0.5^{*}$ \\
\hline GSH $^{2}$ & $100.0 \pm 0.4$ & $131.6 \pm 3.9^{*}$ & $85.6 \pm 2.7^{*}$ & $72.9 \pm 1.9^{*}$ \\
\hline SOD $^{3}$ & $100.0 \pm 0.5$ & $88.8 \pm 0.4^{*}$ & $109.9 \pm 0.7^{*}$ & $84.3 \pm 1.2^{*}$ \\
\hline CAT $^{4}$ & $100.0 \pm 1.9$ & $125.4 \pm 11.8^{*}$ & $164.7 \pm 7.7^{*}$ & $99.9 \pm 5.1$ \\
\hline TRR $^{5}$ & $100.0 \pm 4.7$ & $131.9 \pm 4.5^{*}$ & $83.7 \pm 3.1^{*}$ & $14.9 \pm 2.5^{*}$ \\
\hline AChE $^{6}$ & $100.0 \pm 4.0$ & $92.7 \pm 15.8$ & $156.0 \pm 6.9^{*}$ & $8.9 \pm 4.1$ \\
\hline
\end{tabular}

Concentrations used: DHA/ EPA- 25 and $50 \mu \mathrm{M}$; Values are expressed as $\%$ of control; Values are mean \pm SE (6 replicates); Data analyzed by one-way ANOVA followed by post hoc Dunnet test; ${ }^{*} \mathrm{p}<0.05$, compared to control

${ }^{1}$ Reactive oxygen species: pmol DCF/ min/ mg protein; ${ }^{2}$ Reduced glutathione: $\mu \mathrm{g} \mathrm{GSH} / \mathrm{mg}$ protein; ${ }^{3}$ Superoxide dismutase: units/mg protein; ${ }^{4} \mathrm{Catalase}$ : $\mathrm{nmol} \mathrm{H}_{2} \mathrm{O}_{2}$ decomposed/min/mg protein; ${ }^{5}$ Thioredoxin reductase: $\mathrm{nmol}$ substrate/min/mg protein; ${ }^{6}$ Acetylcholinesterase: nmol substrate hydrolyzed/min/mg $\mathrm{protein}$

Table 1: Effect of DHA and EPA exposure (24 h) on ROS/ GSH levels and activities of superoxide dismutase, catalase, thioredoxin reductase and acetylcholinesterase in SH-SY5Y cells.

cell viability as measured by the cell viability assay. Interestingly, DHA exposure $(25 \mu \mathrm{M})$ significantly enhanced the GSH levels in cell models and this finding corroborates the effects of FO on GSH levels in brain regions in vivo [18]. However, DHA at high concentration $(50 \mu \mathrm{M})$ depleted the GSH levels clearly suggesting that its effect on redox status of the cells may be biphasic in nature. Concomitantly, at higher concentration DHA caused increased ROS generation which was accompanied with diminished TRR activity suggesting the prooxidant effect. Similar observations have been reported earlier in human platelets on exposure to DHA in vitro [37]. However, EPA at both low and high concentrations significantly reduced ROS generation suggesting their antioxidant benefits. In the rat model, the ability of FO to enhance TRR activity in brain regions was demonstrated earlier [18]. Likewise in the cell model, TRR activity was enhanced with both DHA and EPA at low concentration $(25 \mu \mathrm{M})$.

In the present study, treatment of cells with DHA or EPA protected against NPA induced cell death. However, the protective effects were more pronounced with DHA at $25 \mu \mathrm{M}$ and EPA at $50 \mu \mathrm{M}$. Further, NPA exposure caused a significant elevation of ROS and depletion of GSH levels clearly suggesting that the cells were subjected to oxidative stress. 


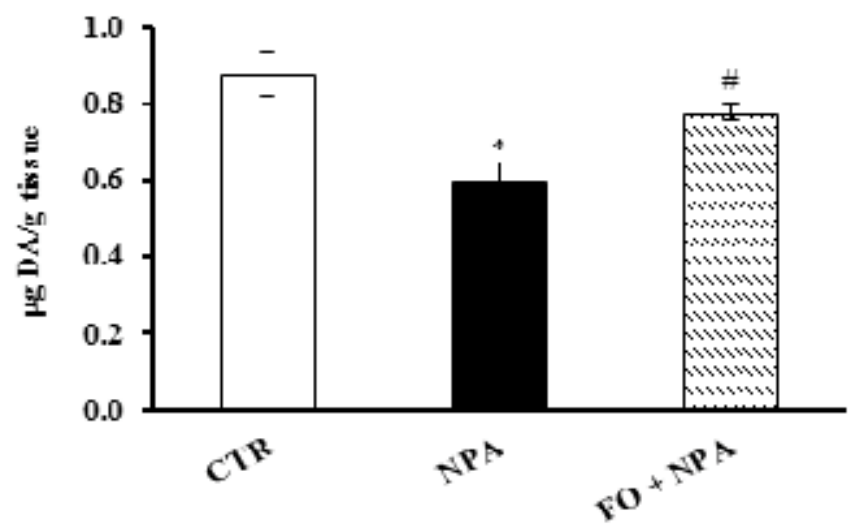

Values are mean \pm SE $(n=6)$; Data analyzed by one-way ANOVA followed by post hoc Tukey test; ${ }^{*} p<0.05$, Compared to Control group; ${ }^{*} p<0.05$, Compared to NPA alone group

Figure 4: Effect of FO prophylaxis $(4 \mathrm{~mL} / \mathrm{kg}$ bw/d) on dopamine levels in striatum among NPA administered rats.

This finding corroborates with the previous findings on the effect of NPA in N27 cells [9]. Interestingly, DHA or EPA significantly offset NPA induced oxidative stress. Further, these findings suggest that DHA may be more potent than EPA, as low concentrations of DHA were found to offer a higher degree of protection compared to EPA. The restoration of activity levels of antioxidant enzymes with DHA or EPA among NPA exposed cells also suggest their efficacy to protect against oxidative stress.

Further, we validated the neuroprotective propensity of $n-3$ fatty acids employing FO, against NPA toxicity in rats. NPA administration caused robust oxidative stress as evidenced by elevated oxidative markers in both cytosol and mitochondria of brain regions. These results are in agreement with previous findings among NPA models of neurotoxicity $[9,38]$. Evidence in experimental animals has clearly shown that NPA affects different brain regions, and striatal neurons were more vulnerable [39]. In this model, FO prophylaxis completely abrogated the oxidative stress response in both cytosol and mitochondrial milieu of striatal regions. This observation clearly suggests the efficacy of FO supplements to regulate oxidative pathways. This finding is also consistent with the findings in cell models with DHA and EPA exposure.

ROS are known to damage all the cellular macromolecules, especially proteins since they can introduce modifications in the side chain of amino acids. These modifications are irreversible such as the introduction of carbonyl groups into the side chain of particular amino acids. Carbonylation causes protein dysfunction and protein aggregation leading to their accumulation during oxidative stress $[40,41]$. This is substantiated by the elevated protein carbonyl levels in St among NPA administered rats. Interestingly FO prophylaxis offered complete protection against NPA induced protein oxidation. It can be speculated that the effects of FO may be mediated through enhancing the antioxidant status and reduction of oxidative stress. A recent report has demonstrated the propensity of $n-3$ fatty acids to reduce protein oxidation in rats [42].

Several lines of evidence demonstrate that excessive NO plays a major role in the pathogenesis of various neurodegenerative diseases such as HD $[43,44]$. In the present study, NPA administered rats exhibited elevated NO levels in both $\mathrm{St}$ and $\mathrm{Cb}$, while $\mathrm{FO}$ prophylaxis attenuated the levels only in St. One of the major mechanisms of NPA induced production of $\mathrm{NO}$ may be mediated through inducible nitric oxide synthase (iNOS) activity, since NPA intoxication has been shown to upregulate iNOS in St [43]. FO supplements have been shown to inhibit iNOS activity in brain regions [45]. Although in the present study the activity levels of iNOS were not measured, it may be speculated that similar mechanisms may be operating in this model.

Glutathione (GSH) is present in all mammalian tissues and is the most abundant non-protein thiol that defends against oxidative stress. GSH is also a key determinant of redox signaling, vital in detoxification of xenobiotics and regulates cell proliferation, apoptosis, immune function and fibrogenesis [46]. NPA administration significantly depleted both GSH and total thiol levels in Cb clearly suggesting the induction of oxidative stress. Complete normalization of GSH levels in $\mathrm{Cb}$ with $\mathrm{FO}$ prophylaxis is clearly suggestive of the specific modulatory effect of FO on redox status of the cells. In contrast, GSH levels were marginally elevated among NPA administered rats in St suggesting a region specific effect. However, FO prophylaxis did not have any significant effect on GSH levels in St. The underlying reasons of the differential implications of NPA in St and $\mathrm{Cb}$ merits further investigation.

In the present model, the effects of NPA on the activity levels of antioxidant enzymes significantly varied from region to region. Among NPA administered rats, SOD activity in St was significantly increased while CAT and GPx activity decreased. Increased SOD activity leads to the increased production of $\mathrm{H}_{2} \mathrm{O}_{2}$ and removal of this requires enhanced GPx or CAT activity [47]. However, increased SOD activity accompanied with decreased GPx and CAT activity results in accumulation of $\mathrm{H}_{2} \mathrm{O}_{2}$ resulting in oxidative stress [47]. This may account for the enhanced oxidative markers in St observed in the present study. Furthermore, the activities of SOD and TRR were significantly decreased in $\mathrm{Cb}$ among NPA administered rats. However, FO prophylaxis offered significant protection against NPA induced perturbations in the activity of antioxidant enzymes in both the regions.

Cholinergic neurotransmission was found to be affected in transgenic mouse model (R6/1) and in tissues from HD patients [48]. In the present study, AChE activity was significantly elevated in St among NPA administered rats. This finding is consistent with earlier reports in which exposure to neurotoxins resulted in significantly elevated AChE activity [49,50]. Increased AChE activity leads to decrease in acetylcholine levels and cholinergic dysfunctions [51]. In the present study, the activity of AChE was completely normalized among rats supplemented with FO suggesting the benefits of $n-3$ fatty acids on cholinergic functions. Galantamine, an AChE inhibitor has been demonstrated to reduce striatal degeneration in NPA model of HD in rats [52]. Further, dopamine levels were significantly depleted among NPA administered rats in St. Earlier studies have shown that DAergic neurons in the substantia nigra are highly sensitive to NPA $[53,54]$. Oxidative stress has been speculated to be a major mechanism underlying NPA induced neuronal damage in St [55]. Interestingly, FO prophylaxis offered complete protection against NPA induced DA depletion clearly suggesting that the protective effect may be mediated through inhibition of oxidative stress.

In the rat model, as anticipated NPA administration significantly diminished the activities of SDH and ETC enzyme complexes. However, FO prophylaxis offered only marginal protection against NPA effects on mitochondria. Though the mitochondrial functions were not significantly improved in the NPA model, FO supplements normalized the oxidative markers, activity of antioxidant enzymes and DA levels in brain regions. Based on this, it may be hypothesized that the neuroprotective effects of FO supplements in the NPA model may be largely mediated by the upregulation of the antioxidant system.

Collectively, the data from in vitro and in vivo models clearly 
Citation: Kollareth DJM, Babu MR, Bharath MMS, Muralidhara M (2017) Fish Oil Prophylaxis Protects against 3-Nitropropinic Acid-Induced Oxidative Impairments in Striatum and Cerebellum in Male Rat Brain

Page 7 of 9

\begin{tabular}{|c|c|c|c|c|c|c|}
\hline Group & CTR & NPA & DHA 25+NPA & DHA 50+NPA & EPA 25+NPA & EPA 50+NPA \\
\hline $\mathrm{ROS}^{1}$ & $100 \pm 7.5$ & $202.1 \pm 3.1^{*}$ & $137.8 \pm 4.5^{*}$ & $219.7 \pm 10$ & $236 \pm 9.5$ & $151.7 \pm 3.2^{\#}$ \\
\hline $\mathrm{GSH}^{2}$ & $100 \pm 3.7$ & $40.5 \pm 3.6^{*}$ & $66.5 \pm 0.4^{*}$ & $57.7 \pm 7.8^{\#}$ & $27.7 \pm 1.8$ & $54.6 \pm 5.1^{\#}$ \\
\hline $\mathrm{SOD}^{3}$ & $100 \pm 0.5$ & $64.0 \pm 1.2^{*}$ & $134.9 \pm 3.4^{\#}$ & $127.5 \pm 10^{\#}$ & $89.5 \pm 1.5^{\#}$ & $90.1 \pm 0.9^{\#}$ \\
\hline $\mathrm{CAT}^{4}$ & $100 \pm 1.9$ & $68.6 \pm 4.3^{*}$ & $164.6 \pm 6.8^{*}$ & $113.1 \pm 5.9^{\#}$ & $132 \pm 9.3^{\#}$ & $122.6 \pm 0.2^{\#}$ \\
\hline $\mathrm{TRR}^{5}$ & $100 \pm 4.7$ & $59.9 \pm 3.4^{*}$ & $80.2 \pm 6.9^{\#}$ & $61.3 \pm 2.3$ & $66.2 \pm 2.3$ & $159.5 \pm 3.8^{\#}$ \\
\hline $\mathrm{AChE}^{6}$ & $100 \pm 4.0$ & $133.1 \pm 19$ & $245.3 \pm 82^{\#}$ & $275.9 \pm 11^{\#}$ & $89.9 \pm 21$ & $110.6 \pm 23$ \\
\hline
\end{tabular}

Concentrations used: NPA- $4 \mathrm{mM}$; DHA/ EPA- 25 and $50 \mu \mathrm{M}$; Values are expressed as $\%$ of control; Values are mean \pm SE (6 replicates); Data analyzed by one-way ANOVA followed by post hoc Tukey test; " $<<0.05$, compared to control; " $p<0.05$, compared to NPA alone group

${ }^{1}$ Reactive oxygen species: pmol DCF/ min/ mg protein; ${ }^{2}$ Reduced glutathione- $\mu \mathrm{ggSH} / \mathrm{mg}$ protein; ${ }^{3}$ Superoxide dismutase: units $/ \mathrm{mg}$ protein; ${ }^{4} \mathrm{Catalase:} \mathrm{nmol} \mathrm{H}_{2} \mathrm{O}_{2}$ decomposed/min/mg protein; ${ }^{5}$ Thioredoxin reductase: $\mathrm{nmol}$ substrate $/ \mathrm{min} / \mathrm{mg}$ protein; ${ }^{6}$ Acetylcholinesterase: $\mathrm{nmol}$ substrate hydrolyzed $/ \mathrm{min} / \mathrm{mg} \mathrm{protein}$

Table 2: Effect of NPA exposure (24 h) on ROS/ GSH levels and activities of superoxide dismutase, catalase, thioredoxin reductase and acetylcholinesterase among SHSY5Y cells pre-exposed with DHA and EPA.

\begin{tabular}{|c|c|c|c|}
\hline Group/Regions & CTR & NPA & FO+NPA \\
\hline \multicolumn{4}{|l|}{ Striatum } \\
\hline \multicolumn{4}{|l|}{ Cytosol } \\
\hline $\mathrm{MDA}^{1}$ & $3.74 \pm 0.2$ & $4.40 \pm 0.2^{*}$ & $3.1 \pm 0.12^{\#}$ \\
\hline $\mathrm{ROS}^{2}$ & $48.1 \pm 1.3$ & $82.2 \pm 4.3^{*}$ & $50.0 \pm 3.9^{\#}$ \\
\hline $\mathrm{HP}^{3}$ & $13.7 \pm 1.3$ & $17.2 \pm 1.2$ & $14.7 \pm 1.3$ \\
\hline \multicolumn{4}{|l|}{ Mitochondria } \\
\hline $\mathrm{MDA}^{1}$ & $1.06 \pm 0.05$ & $1.51 \pm 0.15^{*}$ & $1.34 \pm 0.1$ \\
\hline $\mathrm{ROS}^{2}$ & $9.5 \pm 0.64$ & $10.7 \pm 0.82$ & $9.9 \pm 0.92$ \\
\hline $\mathrm{HP}^{3}$ & $10.1 \pm 0.38$ & $13.6 \pm 1.12^{*}$ & $9.7 \pm 0.2^{\#}$ \\
\hline \multicolumn{4}{|l|}{ Cerebellum } \\
\hline \multicolumn{4}{|l|}{ Cytosol } \\
\hline $\mathrm{MDA}^{1}$ & $3.51 \pm 0.39$ & $6.36 \pm 0.09^{*}$ & $6.57 \pm 0.33$ \\
\hline $\mathrm{ROS}^{2}$ & $98.7 \pm 4.40$ & $92.3 \pm 4.3$ & $64.2 \pm 4.1^{*}$ \\
\hline $\mathrm{HP}^{3}$ & $15.2 \pm 0.75$ & $15.6 \pm 0.93$ & $16.26 \pm 2.5$ \\
\hline \multicolumn{4}{|l|}{ Mitochondria } \\
\hline $\mathrm{MDA}^{1}$ & $1.66 \pm 0.12$ & $1.45 \pm 0.06$ & $1.46 \pm 0.13$ \\
\hline $\mathrm{ROS}^{2}$ & $6.5 \pm 0.13$ & $6.8 \pm 0.33$ & $7.30 \pm 0.02$ \\
\hline $\mathrm{HP}^{3}$ & $11.9 \pm 0.58$ & $10.1 \pm 0.22$ & $10.9 \pm 0.31$ \\
\hline
\end{tabular}

FO- $4 \mathrm{~mL} / \mathrm{kg}$ bw/d, 4 wks; NPA- $25 \mathrm{mg} / \mathrm{kg}$ bw/d, 4d; Values are mean $\pm \mathrm{SE}(\mathrm{n}=6)$; Data analyzed by one-way ANOVA followed by post hoc Tukey test; " $p<0.05$, compared to control group; $\#<<0.05$, compared to NPA group.

${ }^{1}$ Malondialdehyde: $\mathrm{nmol} \mathrm{MDA} / \mathrm{mg}$ protein; ${ }^{2}$ Reactive oxygen species: pmol DCF/min/mg protein; ${ }^{3} \mathrm{Hydroperoxides:} \mathrm{nmol}$ hydroperoxides $/ \mathrm{mg}$ protein

Table 3: Effect of fish oil (FO) prophylaxis on the status of lipid peroxidation (MDA), ROS generation and hydroperoxide levels in cytosol/mitochondria of striatum and cerebellum among NPA administered rats.

\begin{tabular}{|c|c|c|c|}
\hline & CTR & NPA & FO+NPA \\
\hline \multicolumn{4}{|l|}{ Striatum } \\
\hline $\mathrm{GPx}^{1}$ & $15.27 \pm 1.2$ & $10.48 \pm 0.98^{*}$ & $18.38 \pm 0.68^{\#}$ \\
\hline $\mathrm{GR}^{2}$ & $10.48 \pm 1.44$ & $13.28 \pm 0.28$ & $13.8 \pm 0.74^{*}$ \\
\hline $\mathrm{GST}^{3}$ & $63.5 \pm 2.74$ & $70.4 \pm 5.67$ & $61.9 \pm 1.5$ \\
\hline $\mathrm{SOD}^{4}$ & $147.7 \pm 1.43$ & $193.8 \pm 15.6^{*}$ & $145.3 \pm 13.4^{\#}$ \\
\hline $\mathrm{CAT}^{5}$ & $4.32 \pm 0.14$ & $2.93 \pm 0.16$ & $3.5 \pm 0.08$ \\
\hline $\mathrm{TRR}^{6}$ & $8.29 \pm 0.39$ & $7.39 \pm 0.45$ & $10.18 \pm 0.8^{\#}$ \\
\hline $\mathrm{AChE}^{7}$ & $565.7 \pm 43.3$ & $630.2 \pm 14.8^{*}$ & $570.0 \pm 10^{\#}$ \\
\hline \multicolumn{4}{|l|}{ Cerebellum } \\
\hline$G P x^{1}$ & $30.37 \pm 3.36$ & $31.61 \pm 2.48$ & $40.7 \pm 2.25^{\#}$ \\
\hline $\mathrm{GR}^{2}$ & $37.6 \pm 0.8$ & $36.4 \pm 1.05$ & $34.8 \pm 0.66$ \\
\hline $\mathrm{GST}^{3}$ & $83.2 \pm 0.65$ & $67.2 \pm 4.07^{*}$ & $80.8 \pm 0.95^{\#}$ \\
\hline $\mathrm{SOD}^{4}$ & $256.2 \pm 13.2$ & $168.3 \pm 13.1^{*}$ & $188.9 \pm 2.6$ \\
\hline $\mathrm{CAT}^{5}$ & $8.69 \pm 0.72$ & $6.93 \pm 0.54$ & $7.7 \pm 0.02$ \\
\hline $\mathrm{TRR}^{6}$ & $10.81 \pm 0.26$ & $5.98 \pm 0.82^{*}$ & $9.3 \pm 1.28^{\#}$ \\
\hline $\mathrm{AChE}^{7}$ & $74.0 \pm 3.9$ & $67.9 \pm 1.73$ & $73.1 \pm 11.08$ \\
\hline
\end{tabular}

FO- $4 \mathrm{~mL} / \mathrm{kg}$ bw/ d, $4 \mathrm{wks}$; NPA- $25 \mathrm{mg} / \mathrm{kg}$ bw/ d, $4 \mathrm{~d}$ Values are mean \pm SE ( $\mathrm{n}=6$ ); Data analyzed by one-way ANOVA followed by post hoc Tukey test. * $\mathrm{p}<0.05$, compared to control group; $\# p<0.05$, compared to NPA group.

${ }^{1}$ Glutathione peroxidase: nmol NADPH oxidized/ $\mathrm{min} / \mathrm{mg}$ protein; ${ }^{2} \mathrm{G}$ lutathione reductase- $\mathrm{nmol}$ NADPH oxidized/ $\mathrm{min} / \mathrm{mg} \mathrm{protein} ;{ }^{3} \mathrm{Glutathione-s-transferase:} \mu \mathrm{mol}$ conjugate/ min/ mg protein; ${ }^{4}$ Superoxide dismutase: units/ $\mathrm{mg}$ protein; ${ }^{5}$ Catalase: $\mathrm{nmol} \mathrm{H}_{2} \mathrm{O}_{2}$ decomposed/ $\mathrm{min} / \mathrm{mg}$ protein; ${ }^{6} \mathrm{Thioredoxin}$ reductase: $\mathrm{nmol}$ substrate/ min/ $\mathrm{mg}$ protein; ${ }^{7} \mathrm{Ace}$ (ylcholinesterase: $\mathrm{nmol}$ substrate hydrolyzed/ $\mathrm{min} / \mathrm{mg}$ protein.

Table 4: Effect of fish oil (FO) prophylaxis on the activities of glutathione peroxidase, glutathione reductase, glutathione-s-transferase, superoxide dismutase, catalase, thioredoxin reductase and acetylcholinesterase in cytosol of brain regions among NPA administered rats. 


\begin{tabular}{|c|c|c|c|}
\hline & CTR & NPA & FO+NPA \\
\hline \multicolumn{4}{|l|}{ Striatum } \\
\hline $\mathrm{SDH}^{1}$ & $9.1 \pm 1.3$ & $4.1 \pm 0.5^{*}$ & $4.2 \pm 0.4$ \\
\hline NADH- cyt C reductase ${ }^{2}$ & $19.2 \pm 0.4$ & $17.5 \pm 1.5$ & $17.3 \pm 1.8$ \\
\hline Succinate-cyt $\mathrm{C}$ reductase ${ }^{3}$ & $5.7 \pm 1.0$ & $3.5 \pm 0.1^{*}$ & $4.5 \pm 0.4$ \\
\hline \multicolumn{4}{|l|}{ Cerebellum } \\
\hline $\mathrm{SDH}^{1}$ & $12.2 \pm 1.9$ & $5.2 \pm 0.5^{*}$ & $8.3 \pm 0.9$ \\
\hline $\mathrm{NADH}-$ cyt $\mathrm{C}$ reductase ${ }^{2}$ & $25.9 \pm 1.4$ & $13.9 \pm 1.4^{*}$ & $18.7 \pm 2.3$ \\
\hline Succinate-cyt $\mathrm{C}$ reductase ${ }^{3}$ & $7.6 \pm 0.4$ & $2.6 \pm 0.2^{*}$ & $2.7 \pm 0.1$ \\
\hline
\end{tabular}

FO- $4 \mathrm{~mL} / \mathrm{kg}$ bw/d, 4 wks; NPA- $25 \mathrm{mg} / \mathrm{kg}$ bw/d, $4 \mathrm{~d}$; Values are mean $\pm \mathrm{SE}(\mathrm{n}=6)$ Data analyzed by one-way ANOVA followed by post hoc Tukey test; " $p<0.05$, compared to control group; ${ }^{*} \mathrm{p}<0.05$, compared to NPA alone group.

${ }^{1}$ Succinate dehydrogenase: $\mathrm{OD}$ at $490 \mathrm{~nm} / \mathrm{mg}$ protein; ${ }^{2} \mathrm{NADH}$ - cyt $\mathrm{C}$ reductase: $\mathrm{nmol}$ cyt $\mathrm{C}$ reduced $/ \mathrm{min} / \mathrm{mg}$ protein; ${ }^{3}$ Succinate- cyt $\mathrm{C}$ reductase: $\mathrm{nmol}$ cyt $\mathrm{C}$ reduced $/ \mathrm{min} / \mathrm{mg}$ protein

Table 5: Effect of fish oil (FO) prophylaxis on the activities of succinate dehydrogenase, $\mathrm{NADH}$ - cyt $\mathrm{C}$ reductase and succinate- cyt $\mathrm{C}$ reductase in mitochondria of brain regions among NPA administered rats.

suggests the beneficial effects of $n-3$ fatty acids against NPA induced oxidative stress and neurotoxicity. DHA was found to be more beneficial compared to EPA as lower concentrations offered higher protection against NPA induced cytotoxicity. Further, data obtained in vivo suggests that beneficial effects of FO may be mediated through enhanced antioxidant status. In conclusion, our study has shown that n-3 PUFA supplementation may offer a potential neuroprotective strategy in oxidative stress mediated neurodegenerative conditions.

\section{Acknowledgements}

We wish to thank the Director, CFTRI for his keen interest in this study. The first author thanks the Council of Scientific and Industrial research (CSIR), New Delhi, Govt. of India for the award of Junior/ Senior Research Fellowships.

\section{References}

1. Pascoe MC, Howells DW, Crewther DP, Carey LM, Crewther SG, et al. (2015) Fish oil supplementation associated with decreased cellular degeneration and increased cellular proliferation 6 weeks after middle cerebral artery occlusion in the rat. Neuropsychiatric disease and treatment 11: 153.

2. Zhu H, Fan C, Xu F, Tian C, Zhang F, et al. (2010) Dietary fish oil n-3 polyunsaturated fatty acids and alpha-linolenic acid differently affect brain accretion of docosahexaenoic acid and expression of desaturases and sterol regulatory element-binding protein 1 in mice. The Journal of nutritional biochemistry 21: 954-960.

3. Russell KL, Berman NEJ, Gregg PRA, Levant B (2014) Fish oil improves motor function, limits blood-brain barrier disruption, and reduces Mmp9 gene expression in a rat model of juvenile traumatic brain injury. Prostaglandins Leukot Essent Fatty Acids 90: 5-11.

4. Haraguchi T, Yanaka N, Eguchi Y, Kudo T, Hirata A, et al. (2011) Fish Oi Feeding Up-Regulates the Expression of 5-Aminolevulinate Synthase 2 mRNA in Rat Brain. Bioscience, biotechnology, and biochemistry 75: 1383-1385.

5. Taepavarapruk P, Song C (2010) Reductions of acetylcholine release and nerve growth factor expression are correlated with memory impairment induced by interleukin-1 beta administrations: effects of omega-3 fatty acid EPA treatment. J Neurochem 112: 1054-1064.

6. Gupta S, Sharma B (2014) Protective effects of phosphodiesterase-1 (PDE1) and ATP sensitive potassium (KATP) channel modulators against 3-nitropropionic acid induced behavioral and biochemical toxicities in experimental Huntington's disease. Eur J Pharmacol 732: 111-122.

7. Solesio ME, Saez-Atienzar S, Jordan J, Galindo MF (2013) 3-Nitropropionic acid induces autophagy by forming mitochondrial permeability transition pores rather than activating the mitochondrial fission pathway. $\mathrm{Br} \mathrm{J}$ Pharmacol 168: 63-75

8. Cho KJ, Kim HW, Cheon SY, Lee JE, Kim GW, et al. (2013) Apoptosis signalregulating kinase-1 aggravates ROS-mediated striatal degeneration in 3-nitropropionic acid-infused mice. Biochem Biophys Res Commun 441: 280-285.
9. Shinomol GK, Bharath MMS, Muralidhara M (2012) Neuromodulatory propensity of Bacopa monnieri leaf extract against 3-nitropropionic acid-induced oxidative stress: in vitro and in vivo evidences. Neurotox Res 22: 102-114.

10. Mahdy HM, Mohamed MR, Emam MA, Karim AM, Abdel-Naim A, et al. (2014) Puerarin Ameliorates 3-Nitropropionic Acid-Induced Neurotoxicity in Rats: Possible Neuromodulation and Antioxidant Mechanisms. Neurochem Res 39: 321-332.

11. Tian C, Kim YH, Kim YC, Park KT, Kim SW, et al. (2013) Korean red ginseng ameliorates acute 3-nitropropionic acid-induced cochlear damage in mice. Neurotoxicology 34: 42-50.

12. Colle D, Santos DB, Hartwig JM, Godoi M, Engel DF, et al. (2016) Succinobucol, a Lipid-Lowering Drug. Protects Against 3-Nitropropionic AcidInduced Mitochondrial Dysfunction and Oxidative Stress in SH-SY5Y Cells via Upregulation of Glutathione Levels and Glutamate Cysteine Ligase Activity. Mol Neurobiol 53: 1280-1295.

13. Hashimoto M, Katakura M, Hossain S, Rahman A, Shimada T, et al. (2011) Docosahexaenoic acid withstands the $A \beta(25-35)$-induced neurotoxicity in $\mathrm{SH}$ SY5Y cells. J Nutr Biochem 22: 22-29.

14. Luchtman DW, Song C (2013) Cognitive enhancement by omega-3 fatty acids from child-hood to old age: Findings from animal and clinical studies. Neuropharmacology 64: 550-565

15. Wu H, Ichikawa S, Tani C, Zhu B, Tada M, et al. (2009) Docosahexaenoic acid induces ERK1/2 activation and neuritogenesis via intracellular reactive oxygen species production in human neuroblastoma SH-SY5Y cells. Biochim Biophys Acta 1791: 8-16.

16. Encinas M, Iglesias M, Liu Y, Wang H, Muhaisen A, et al. (2000) Sequentia treatment of SH-SY5Y cells with retinoic acid and brain-derived neurotrophic factor gives rise to fully differentiated, neurotrophic factor-dependent, human neuron-like cells. J Neurochem 75: 991-1003.

17. Luchtman DW, Meng Q, Wang X, Shao D, Song C, et al. (2013) $\omega-3$ fatty acid eicosapentaenoic acid attenuates MPP+-induced neurodegeneration in fully differentiated human SH-SY5Y and primary mesencephalic cells. J Neurochem 124: 855-868.

18. Denny Joseph KM, Muralidhara M (2012) Fish oil prophylaxis attenuates rotenone-induced oxidative impairments and mitochondrial dysfunctions in rat brain. Food Chem Toxicol 50: 1529-1537.

19. Binawade Y, Jagtap A (2013) Neuroprotective effect of lutein against 3-nitropropionic acid-induced Huntington's disease-like symptoms: possible behavioral, biochemical, and cellular alterations. J Med Food 16: 934-943.

20. Moreadith RW, Fiskum G (1984) Isolation of mitochondria from ascites tumor cells permeabilized with digitonin. Anal Biochem 137: 360-367.

21. Ohkawa H, Ohishi N, Yagi K (1979) Assay for lipid peroxides in animal tissues by thiobarbituric acid reaction. Anal Biochem 95: 351-358.

22. Wolff SP (1994) Ferrous ion oxidation in presence of ferric ion indicator xyleno orange for measurement of hydroperoxides. Methods Enzymol 233C: 182-189.

23. Levine RL, Garland D, Oliver CN, Amici A, Climent I, et al. (1990) Determination of carbonyl content in oxidatively modified proteins. Methods Enzymol 186: 464-478.

24. Mokrasch LC, Teschke EJ (1984) Glutathione content of cultured cells and rodent brain regions: a specific fluorometric assay. Anal Biochem 140: 506-509.

25. Kostyuk VA, Potapovich Al (1989) Superoxide-driven oxidation of quercetin and a simple sensitive assay for determination of superoxide dismutase. Biochem Int 19: 1117-1124.

26. Aebi H (1984) Catalase in vitro. Methods Enzymol 105: 121-126.

27. Luthman M, Holmgren $A(1982)$ Rat liver thioredoxin and thioredoxin reductase: purification and characterization. Biochemistry (Mosc) 21: 6628-6633.

28. Guthenberg C, Alin P, Mannervik B (1985) Glutathione transferase from rat testis. Methods Enzymol 113: 507-510.

29. Flohé L, Günzler WA (1984) Assays of glutathione peroxidase. Methods Enzymol 105: 114-121.

30. Ellman GL, Courtney KD, Andres V, Feather-Stone RM (1961) A new and rapid colorimetric determination of acetylcholinesterase activity. Biochem Pharmacol 7: 88-95. 
Citation: Kollareth DJM, Babu MR, Bharath MMS, Muralidhara M (2017) Fish Oil Prophylaxis Protects against 3-Nitropropinic Acid-Induced Oxidative Impairments in Striatum and Cerebellum in Male Rat Brain

31. Dalpiaz A, Filosa R, de Caprariis P, Conte G, Bortolotti F, et al. (2007) Molecular mechanism involved in the transport of a prodrug dopamine glycosyl conjugate. Int J Pharm 336: 133-139.

32. Pennington RJ (1961) Biochemistry of dystrophic muscle. Mitochondrial succinate-tetrazolium reductase and adenosine triphosphatase. Biochem $\mathrm{J} 80$ : 649-654

33. Navarro A, Gomez C, López-Cepero JM, Boveris A (2004) Beneficial effects of moderate exercise on mice aging: survival, behavior, oxidative stress, and mitochondrial electron transfer. Am J Physiol Regul Integr Comp Physiol 286: R505-511.

34. Lowry OH, Rosebrough NJ, Farr AL, Randall RJ (1951) Protein measurement with the Folin phenol reagent. J Biol Chem 193: 265-275.

35. Kidd PM (2007) Omega-3 DHA and EPA for cognition, behavior, and mood: clinical findings and structural-functional synergies with cell membrane phospholipids. Altern Med Rev J Clin Ther 12: 207-227.

36. Kou W, Luchtman D, Song C (2008) Eicosapentaenoic acid (EPA) increases cell viability and expression of neurotrophin receptors in retinoic acid and brain-derived neurotrophic factor differentiated SH-SY5Y cells. Eur J Nutr 47: 104-113.

37. Véricel E, Polette A, Bacot S, Calzada C, Lagarde M, et al. (2003) Pro- and antioxidant activities of docosahexaenoic acid on human blood platelets. J Thromb Haemost 1: 566-572.

38. Herrera-Mundo N, Sitges M (2013) Vinpocetine and a-tocopherol prevent the increase in DA and oxidative stress induced by 3-NPA in striatum isolated nerve endings. J Neurochem 124: 233-240.

39. Singh S, Misiak M, Beyer C, Arnold S (2010) Brain region specificity of 3-nitropropionic acid-induced vulnerability of neurons involves cytochrome c oxidase. Neurochem Int 57: 297-305.

40. Dalle-Donne I, Scaloni A, Giustarini D, Cavarra E, Tell G, et al. (2005) Proteins as biomarkers of oxidative/nitrosative stress in diseases: the contribution of redox proteomics. Mass Spectrom Rev 24: 55-99.

41. Stadtman ER (2006) Protein oxidation and aging. Free Radic Res 40: 1250-1258.

42. Méndez L, Pazos M, Gallardo JM, Torres JL, Pérez-Jiménez J, et al. (2013) Reduced protein oxidation in Wistar rats supplemented with marine $\omega 3$ PUFAs. Free Radic Biol Med 55: 8-20.

43. Deshpande SB, Hida H, Takei-lo N, Masuda T, Baba H, et al. (2006) Involvement of nitric oxide in 3-nitropropionic acid-induced striatal toxicity in rats. Brain Res 1108: 205-215
44. Kumar P, Kumar A (2009) Neuroprotective effect of cyclosporine and FK506 against 3-nitropropionic acid induced cognitive dysfunction and glutathione redox in rat: possible role of nitric oxide. Neurosci Res 63: 302-314.

45. Bancroft LK, Lupton JR, Davidson LA, Taddeo SS, Murphy M, et al. (2003) Dietary fish oil reduces oxidative DNA damage in rat colonocytes. Free Radic Biol Med 35: 149-159.

46. Lu SC (2013) Glutathione synthesis. Biochim Biophys Acta 1830: 3143-3153.

47. Halliwell $B$ (2006) Oxidative stress and neurodegeneration: where are we now? J Neurochem 97: 1634-1658.

48. Smith R, Chung H, Rundquist S, Maat-Schieman ML, Colgan L, et al. (2006) Cholinergic neuronal defect without cell loss in Huntington's disease. Hum Mol Genet 15: 3119-3131.

49. Girish C, Muralidhara M (2012) Propensity of Selaginella delicatula aqueous extract to offset rotenone-induced oxidative dysfunctions and neurotoxicity in Drosophila melanogaster: Implications for Parkinson's disease. Neurotoxicology 33: 444-456.

50. Prasad SN, Muralidhara M (2013) Neuroprotective efficacy of eugeno and isoeugenol in acrylamide-induced neuropathy in rats: behavioral and biochemical evidence. Neurochem Res 38: 330-345.

51. Bhutada P, Mundhada Y, Bansod K, Tawari S, Patil S, et al (2011) Protection of cholinergic and antioxidant system contributes to the effect of berberine ameliorating memory dysfunction in rat model of streptozotocin-induced diabetes. Behav Brain Res 220: 30-41.

52. Park JE, Lee ST, Im WS, Chu K, Kim M, et al. (2008) Galantamine reduces striatal degeneration in 3-nitropropionic acid model of Huntington's disease. Neurosci Lett 448: 143-147.

53. Al Mutairy A, Al Kadasah S, Elfaki I, Arshaduddin M, Malik D, et al. (2010) Trolox ameliorates 3-nitropropionic acid-induced neurotoxicity in rats. Neurotoxicol Teratol 32: 226-233.

54. Nishino H, Kumazaki M, Fukuda A, Fujimoto I, Shimano $Y$, et al. (1997) Acute 3-nitropropionic acid intoxication induces striatal astrocytic cell death and dysfunction of the blood-brain barrier: involvement of dopamine toxicity. Neurosci Res 27: 343-355.

55. Wu CL, Hwang CS, Chen SD (2010) Neuroprotective mechanisms of brainderived neurotrophic factor against 3-nitropropionic acid toxicity: therapeutic implications for Huntington's disease. Ann NY Acad Sci 1201: 8-12. 